\title{
Effect of some plant extracts against the greater wax moth Galleria mellonella $\mathbf{L}$.
}

\author{
Soliman M.M.M. ${ }^{1}$, K.M. Mohanny ${ }^{2}$, H.M. Mansour ${ }^{3}$, and M.A. Seddik ${ }^{4^{*}}$ \\ ${ }^{1}$ Plant Protection Department, Faculty of Environmental Agriculture, Technology and Food \\ Sciences, Beni-Suef University, Egypt. \\ ${ }^{2}$ Plant Protection Department, Faculty of Agriculture, South Valley University, Qena, Egypt. \\ ${ }^{3}$ Head researcher of plant protection research institute (PPRI), Apiculture Research \\ Department. (Agriculture Research Center) \\ ${ }^{4}$ PhD Candidate, (Plant Protection Department, Faculty of Agriculture, South Valley \\ University), Plant protection institute, Agriculture Research Center.
}

\begin{abstract}
The present study was carried out to evaluate the biochemical effects of four plants extracts (D. stramonium L., Hyoscyamus muticus L., Nerium oleander L. and Eucalyptus camalulensis Dehn.) on the late instar larvae of the greater wax moth Galleria mellonella L. The results showed that treatment of $D$. stramonium L. $4 \%$ gave the maximum total mortality percentage $(73.33 \%)$, while the minimum total mortality percentage was $(13.33 \%)$ which recorded by $N$. oleander L. 4\%. Biological parameters were studied under laboratory conditions, the life cycle decreased by increasing plant extract concentrations. The life cycle could be arranged in ascending order as follow: 58.33, 56.67, 62.67 and 69.00 day for the larvae treated with D. stramonium L. 4\%, Sakran 4\%, E. Camalulensis Dehn., and N. oleander L. 4\%, respectively.
\end{abstract}

Key words: Galleria mellonella, Plant extracts, Biological parameters, Mortality percentage.

\section{Introduction}

The honeybee is the most useful insect to man. Honeybee is attacked by many diseases and pests which cause weakness of colonies and honey production. Like the Greater Wax Moths Gallaria mellonella L. which is the most serious pest of honeybee combs (Hachiro and David, 2000).

*Corresponding author: Mostafa Seddik,

Email: eng_mostafa388@yahoo.com

Received: June 29, 2019;

Accepted: September 10, 2019;

Published: October 10, 2019.
The greater wax moth (GWM) Galleria mellonella (Lepidoptera:Pyralidae) is the most serious pest of honeybee wax combs in storage places and can cause substantial losses to combs, hive material and bees in beehives all over the world.

The natural compound with high insecticidal activity against the wax moth and with low toxic effects to honeybees is essential. This will enable their use in integrated pest management programs to control wax moth in honeybee colonies as well as in storage areas without contaminating honey bee products with pesticide residues. This work aimed to 
determine the efficacy of D.stramonium L., Hyoscyamus muticus L, Nerium oleander L., and Eucalyptus camalulensis Dehn. extracts against late larval instar of the greeter wax moth, G. mellonella, as natural control agents and to study their effect on some biological aspects of the insect.

\section{Material and Methods}

\section{Preparation of Tested plants extracts}

Tested plants were exposed to an extraction process according to the method described by Ellis and Hayes (2009). Each sample (100 g) was extracted by using acetone solvent. Dry ground materials were placed in flasks (1/2 liter), filled with acetone solvent and left for $24 \mathrm{hr}$. at room temperature. The flasks were plugged and shaken in an electric shaker, and then the suspensions were filtered through Whitman no.1 filter paper. The solvents were evaporated from the filtrate by leaving it at the room temperature to obtain crude extracts. Ten grams of each crude was dissolved in $100 \mathrm{ml}$ acetone according to Roman et al., (2009) to obtain a $10 \%$ stock solution (w/v), which was stored under refrigeration until needed. This stock solution was serially diluted by the solvent as required for the bioassay tests.

Table 1. Source of the tested plants

\begin{tabular}{lccc}
\hline \multicolumn{1}{c}{ English name } & Scientific name & Family & Used part \\
\hline Jimsonweed & Datura stramonium $L$. & Solanaceae & Leaves \\
Egyptian henbane & Hyoscyamus muticus $\mathrm{L}$ & Solanaceae & Leaves \\
Nerium & Nerium oleander L & Apocynaceae & Leaves \\
Camphor & Eucalyptus camalulensis & Myrtaceae & Leaves \\
\hline
\end{tabular}

\section{Toxicity of tested plant extracts against G. mellonella larvae}

Tested materials were applied as liquid formulations of acetone extraction, sprayed on the pieces of wax at Petri dishes $(10 \mathrm{~cm})$ under laboratory conditions, where $4.0 \%$ concentrations of each extract were prepared from the stock solutions (100\%). Ten individuals of late instar larvae of $G$. mellonella were placed in each Petri dish, which contained $20 \mathrm{~g}$ of small pieces of pure wax. One $\mathrm{ml}$ of the $4.0 \%$ concentration was added to the dish above the larvae and closed with other dish to prevent escaping of larvae. Daily observations were done to count the number of dead individuals. All treatments were replicated three times. The $\mathrm{LC}_{50}$ and $\mathrm{LC}_{90}$ values were estimated from the toxicity lines of the tested materials according to Finney (1971).

\section{Effect of tested plant extracts on some biological aspects of G. mellonella.}

Effect of the four concentrations of each extract $(0.5,1.0,2.0$, and $4.0 \%)$ from the stock solutions $(100 \%)$, on some 
biological aspects of $G$. mellonella when applied as liquid fonnulations of acetone extraction sprayed on the pieces of wax at Petri dishes under laboratory conditions, was studied according to Pastagia and Patel, (2007). Ten newly hatched instar larvae of the greater wax moth were placed in each dish which contained $20 \mathrm{~g}$ of small pieces of pure wax, and then $5 \mathrm{ml}$ of the least concentration of each tested material was added to the dish above the pieces of wax and closed with other dish to prevent escaping of larvae. Treatments were replicated three times. Different biological aspects; larval and pupal durations, adult longevity, ovipositional period, incubation period, life cycle, hatchability was recorded. Experiments were conducted under the laboratory conditions of $23 \pm 2{ }^{\circ} \mathrm{C}$ and $50 \pm 5 \% \mathrm{RH}$.

The collected data through different experiments were subjected to one way analysis of variance according to method of Gomez and Gomez (1984).

\section{Result and Discussion}

\section{The efficiency of plant extracts on greater wax moth.}

\section{Mortality percentage of the $5^{\text {th }}$ instar larvae}

Data of Table (2) indicate that the mortality $\%$ increased with increasing the time of exposure, reaching its maximum after 72 hours. The highest mortality $(73.33 \%)$ was obtained by $D$. stramonium, followed by $H$. muticus $(56.67 \%)$. and $E$. Camalulensis. (30.00\%), while the lowest mortality $(13.33 \%)$ was recorded by $N$. oleander, and no mortality \% was recorded by the untreated larvae. These results are in harmony with those obtained by
Abbasipour et al. (2011) who showed that the mortality increased with increased concentrations of D. stramonium and exposure time. After $12 \mathrm{~h}$, high increase in mortality was recorded. These results suggest that the extract of $D$. stramonium may be of high value in grain storage against Callosobruchus maculatus, especially in subsistence agriculture where the plants are locally available to farmers with little resources to meet the high cost of pesticides.

Malika et al. (2016) found that the synergistic extract of $N$. oleander caused a remarkable mortality rate of larvae of Tuta absoluta that exceeded 90\%. N. oleander presented a low toxicity not exceeding $30 \%$ for the hydro-ethanolic extracts and $40 \%$ for the hydro-methanoic extracts.

\section{$L_{50}$ and $L C_{90}$ of plant extracts against the $5^{\text {th }}$ instar larvae.}

Table (2) and Fig. (1) indicate that $\mathrm{LC}_{50}$ and $\mathrm{LC}_{90}$ values of the used plant extracts for D.stramonium, H. muticus, E. Camalulensis and $N$. oleander were (1.61 \& 11.90), (3.23 \& 34.94), (9.22 \& 70.60$)$ and (18.52 \& 114.06) g/L respectively.

Malika et al. (2016) found that after 24 hours of exposure to the test, the $\mathrm{LD}_{50}$ values were very high (above 50\%) for hydro-ethanolic and hydro-methanoic extracts for the two plants used (Nerium oleander and Ricinus communis). However, the $\mathrm{LD}_{50}$ values were relatively low for the synergistic extract (19\%). The results showed that second instar and first instar larvae are more sensitive to all used extracts. The third instar and fourth instar are the most resistant, except for the synergistic extract. 
Table 2. Mortality $\%$ as well as $\mathrm{LC}_{50}$ and $\mathrm{LC}_{90}$ of the $5^{\text {th }}$ instar larvae of $G$. mellonella treated with plant extracts of $4 \%$ concentration.

\begin{tabular}{|c|c|c|c|c|c|c|c|c|}
\hline \multirow{2}{*}{ Materials } & \multicolumn{3}{|c|}{ Mortality $\%$ after } & \multirow{2}{*}{ Total } & \multirow{2}{*}{ Mean } & \multirow{2}{*}{$\mathrm{LC}_{50}$} & \multirow{2}{*}{$\mathrm{LC}_{90}$} & \multirow{2}{*}{$\begin{array}{c}\text { Slope } \pm \\
\text { SE }\end{array}$} \\
\hline & $24 \mathrm{~h}$ & $48 \mathrm{~h}$ & $72 \mathrm{~h}$ & & & & & \\
\hline D. stramonium & 13.33 & 23.33 & 36.67 & 73.33 & 24.44 & 1.61 & 11.90 & $1.47 \pm 0.38$ \\
\hline H. muticus & 3.33 & 20.00 & 33.34 & 56.67 & 18.89 & 3.23 & 34.94 & $1.24 \pm 0.40$ \\
\hline$N$. oleander & 0.00 & 6.67 & 6.66 & 13.33 & 4.44 & 18.52 & 114.06 & $1.62 \pm 0.90$ \\
\hline E. Camalulensis & 0.00 & 16.67 & 13.33 & 30.00 & 10.00 & 9.22 & 70.60 & $1.08 \pm 0.48$ \\
\hline Control & 0.00 & 0.00 & 0.00 & 0.00 & 0.00 & & & \\
\hline
\end{tabular}

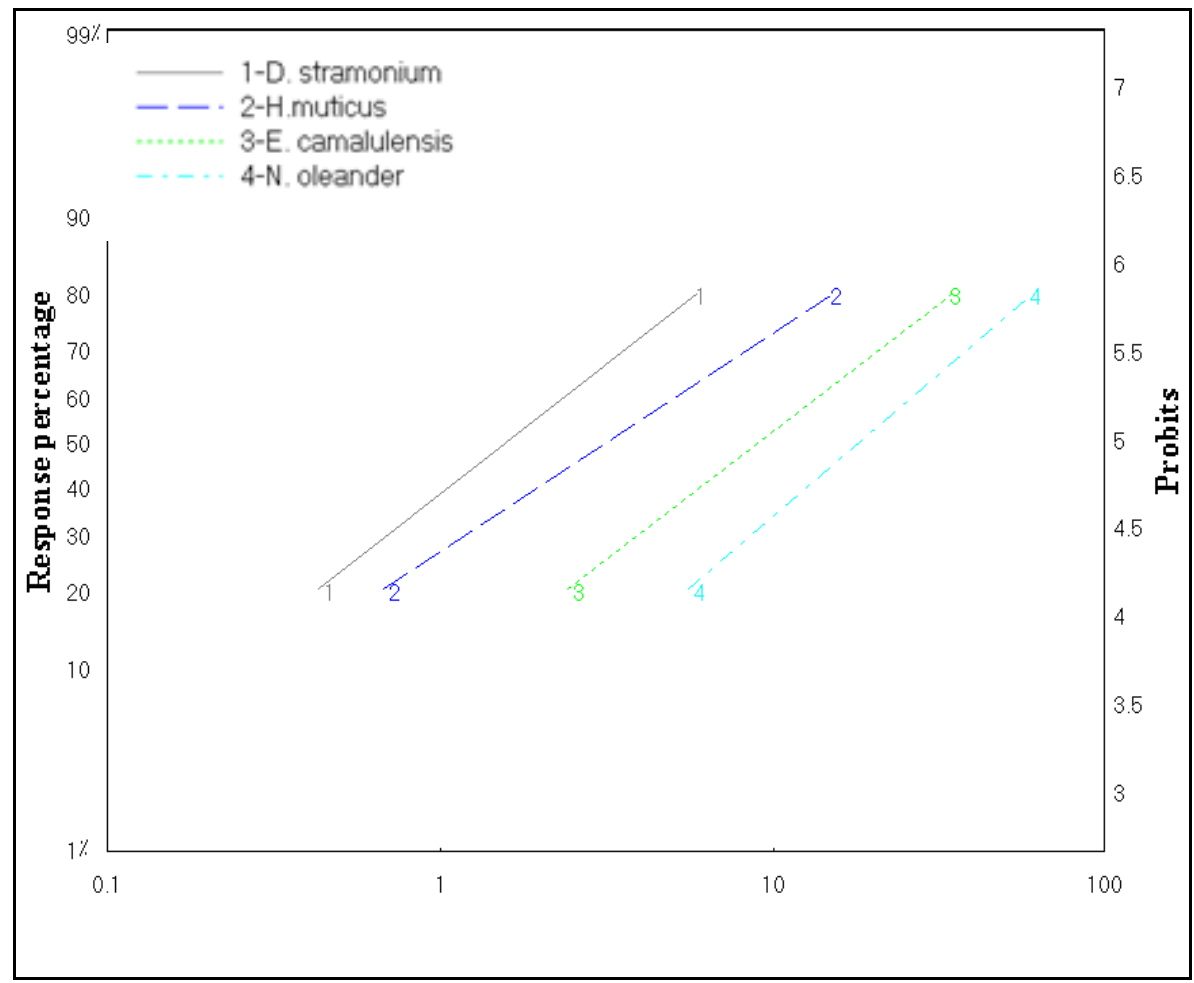

Figure 1. Bioassay of different plant extracts against the last larval instar of G. mellonella. 
Effect of plant extracts on some biological aspects of G.mellonella under laboratory conditions.

Data presented in Table (3) and Fig. (2) describe the effect of different concentrations of $D$. stramonium on some biological aspects (larval and pupal periods, adult longevity, oviposition period, incubation period and consequently the life cycle ) of G.mellonella under laboratory condition. The obtained results show that:

The duration of larval stage decreased by increasing $D$. stramonium concentrations (17.00 days at $4 \%$ concentration, and 32.33 days at $0.5 \%$ in comparison with 39.33 day at control). There were significant differences among all cases.

Pupal duration, adult longevity, and oviposition period also decreased by increasing D. stramonium concentrations. Statistical analysis proved that there were significant differences between adult longevity, and insignificant for the other two parameters.

On contrast, the incubation period increased by increasing $D$. stramonium concentrations, without significant differences.

The life cycle decreased by increasing $D$. stramonium concentrations, (58.33 days at $4 \%$ concentration, 76.00 days at $0.5 \%$ in comparison with 84.67 day at control). There were significant differences among all cases.

\section{Effect of $H$. muticus $L$. against G.mellonella}

Data presented in Table (4) and Fig. (3) describe the effect of different concentrations of $\mathrm{H}$. muticus on some biological aspect of G.mellonella. The data show that:
The duration of larval and pupal stages, adult longevity, oviposition period and incubation period, decreased by increasing H. muticus concentrations. There were significant differences for larval and incubation period.

The life cycle decreased by increasing $H$. muticus concentrations (56.67 days at $4 \%$ concentration, 76.00 days at $0.5 \%$ in comparison with 84.33 day at control), with significant differences between concentrations and control.

\section{Effect of $N$. oleander $L$ against $G$. mellonella}

Data presented in Table (5) and Fig. (4) describe the effect of different concentrations of $N$. oleander on some biological aspect of G.mellonella as follows:

The duration of larval and pupal stages, adult longevity, oviposition period and incubation period, decreased with increasing $N$. oleander concentrations. There were significant differences for all cases except for pupal and oviposition periods.

The life cycle decreased by increasing $N$. oleander concentrations, (69.00 days at 4 $\%$ concentration, 78.33 days at $0.5 \%$ in comparison with 83.67 day at control), with significant differences between concentrations and control. Effect of $\boldsymbol{E}$.

Camalulensis Dehn. against G. mellonella

Data presented in Table (6) and Fig. (5) describe the effect of different concentrations of $\boldsymbol{E}$. Camalulensis on some biological aspects of G.mellonella. 
Table 3. Effect of different concentrations of $D$. stramonium L. extract on some biological aspects of $G$. mellonella under laboratory conditions

\begin{tabular}{ccccccc}
\hline \multirow{2}{*}{\begin{tabular}{c} 
D.stramonium $\begin{array}{c}\text { Duration period in days } \\
\text { Conc. }\end{array}$ \\
\cline { 2 - 7 }
\end{tabular}} & Larvae & Pupa & $\begin{array}{c}\text { Longevity } \\
\text { of adults }\end{array}$ & $\begin{array}{c}\text { Oviposition } \\
\text { Period }\end{array}$ & $\begin{array}{c}\text { Incubation } \\
\text { period }\end{array}$ & $\begin{array}{c}\text { Life } \\
\text { cycle }\end{array}$ \\
\hline $0.5 \%$ & 32.33 & 13.67 & 13.67 & 5.67 & 11.67 & $\mathbf{7 6 . 0 0}$ \\
$2.00 \%$ & 20.67 & 13.00 & 12.33 & 5.33 & 12.33 & $\mathbf{6 3 . 3 3}$ \\
$4.00 \%$ & 17.00 & 12.00 & 11.33 & 5.00 & 13.00 & $\mathbf{5 8 . 3 3}$ \\
Control & 39.33 & 12.33 & 14.67 & 6.33 & 12.00 & $\mathbf{8 4 . 6 7}$ \\
LSD 0.05 & 2.13 & N.S & 2.03 & N.S & N.S & $\mathbf{3 . 4 4}$ \\
\hline
\end{tabular}

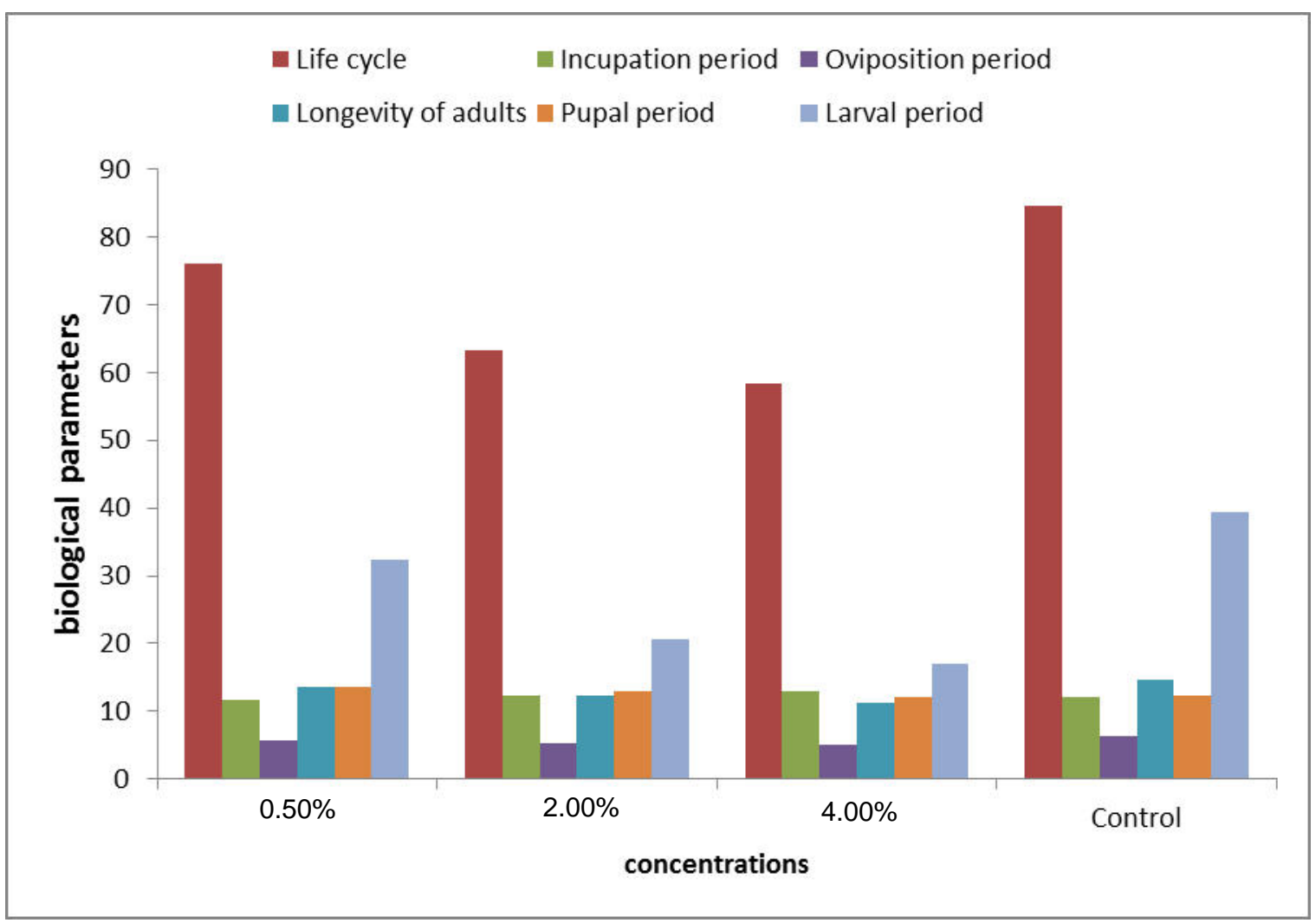

Figure 2. Effect of different concentrations of D. stramonium L. extract on some biological aspects of $G$. mellonella under laboratory conditions. 
Table 4. Effect of different concentrations of $H$. muticus L. extract on some biological aspects of $G$. mellonella under laboratory conditions

\begin{tabular}{ccccccc}
\hline \multirow{2}{*}{$\begin{array}{c}\text { H. muticus } \\
\text { Conc. }\end{array}$} & Larvae & Pupa & $\begin{array}{c}\text { Longevity of } \\
\text { adults }\end{array}$ & $\begin{array}{c}\text { Oviposition } \\
\text { period }\end{array}$ & $\begin{array}{c}\text { Incubation } \\
\text { period }\end{array}$ & $\begin{array}{c}\text { Life } \\
\text { Cycle }\end{array}$ \\
\cline { 2 - 7 } & & 11.67 & 13.00 & 6.00 & 12.00 & $\mathbf{7 6 . 0 0}$ \\
$0.5 \%$ & 33.33 & 11.33 & 12.67 & 5.67 & 11.00 & $\mathbf{6 4 . 3 3}$ \\
$2.00 \%$ & 23.67 & 11.67 & 5.67 & 10.33 & $\mathbf{5 6 . 6 7}$ \\
$4.00 \%$ & 18.33 & 10.67 & 14.33 & 6.33 & 12.33 & $\mathbf{8 4 . 3 3}$ \\
Control & 39.00 & 12.33 & N.S & N.S & 0.67 & $\mathbf{3 . 9 8}$ \\
LSD 0.05 & 2.21 & N.S & N.S
\end{tabular}

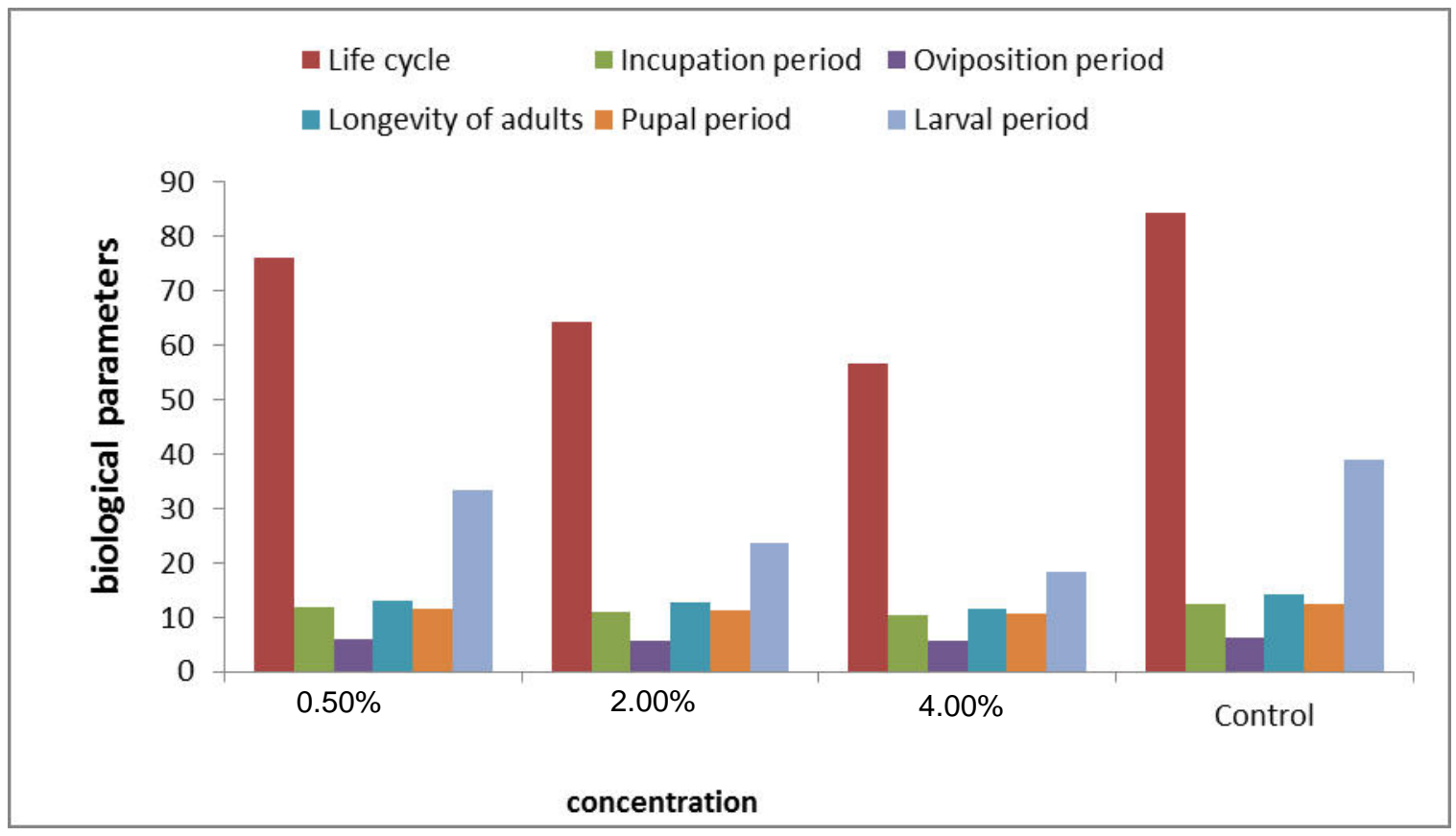

Figure 3. Effect of different concentrations of $H$. muticus L. extract on some biological aspects of $G$. mellonella under laboratory conditions 
Table 5. Effect of different concentrations of $N$. oleander L. extract on some biological aspects of $G$. mellonella under laboratory conditions

\begin{tabular}{ccccccc}
\hline \begin{tabular}{c} 
N. oleander $\begin{array}{c}\text { Duration period in days } \\
\text { Conc. }\end{array}$ \\
\cline { 2 - 7 }
\end{tabular} & Larvae & Pupa & $\begin{array}{c}\text { Longevity of } \\
\text { adults }\end{array}$ & $\begin{array}{c}\text { Oviposition } \\
\text { Period }\end{array}$ & $\begin{array}{c}\text { Incubation } \\
\text { period }\end{array}$ & $\begin{array}{c}\text { Life } \\
\text { Cycle }\end{array}$ \\
$0.5 \%$ & 34.33 & 12.33 & 12.67 & 6.67 & 12.33 & $\mathbf{7 8 . 3 3}$ \\
\hline $2.00 \%$ & 32.00 & 11.67 & 12.33 & 6.33 & 11.67 & $\mathbf{7 4 . 0 0}$ \\
$4.00 \%$ & 29.33 & 11.33 & 11.67 & 6.00 & 10.67 & $\mathbf{6 9 . 0 0}$ \\
Control & 38.00 & 12.67 & 14.67 & 6.67 & 12.33 & $\mathbf{8 3 . 6 7}$ \\
LSD 0.05 & 2.03 & N.S & 1.49 & N.S & 0.88 & $\mathbf{3 . 7 2}$ \\
\hline
\end{tabular}

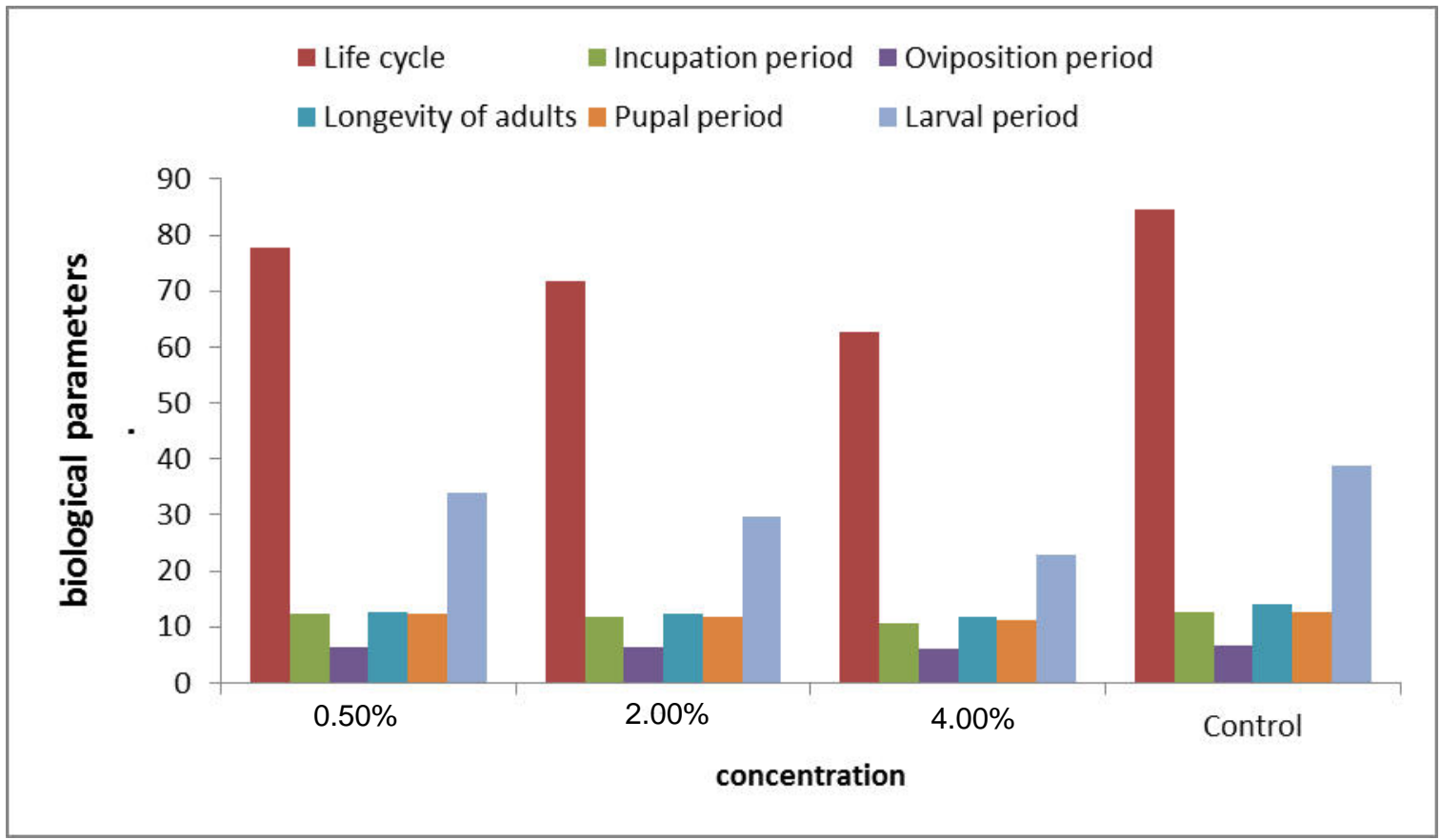

Figure 4. Effect of different concentrations of $N$. oleander L. extract on some biological aspects of $G$. mellonella under laboratory conditions. 
Table 6. Effect of different concentrations of E. Camalulensis Dehn extracts on some biological aspects of $G$. mellonella under laboratory conditions.

\begin{tabular}{ccccccc}
\hline \multirow{2}{*}{$\begin{array}{c}\text { E. } \\
\text { Camalulensis } \\
\text { Conc. }\end{array}$} & Larvae & Pupa & $\begin{array}{c}\text { Longevity } \\
\text { of adults }\end{array}$ & $\begin{array}{c}\text { Oviposition } \\
\text { Period }\end{array}$ & $\begin{array}{c}\text { Incubation } \\
\text { period }\end{array}$ & $\begin{array}{c}\text { Life } \\
\text { Cycle }\end{array}$ \\
\cline { 2 - 7 } & 34.00 & 12.33 & 12.67 & 6.33 & 12.33 & $\mathbf{7 7 . 6 7}$ \\
$0.5 \%$ & 29.67 & 11.67 & 12.33 & 6.33 & 11.67 & $\mathbf{7 1 . 6 7}$ \\
$2.00 \%$ & 23.00 & 11.33 & 11.67 & 6.00 & 10.67 & $\mathbf{6 2 . 6 7}$ \\
$4.00 \%$ & 38.67 & 12.67 & 14.00 & 6.60 & 12.67 & $\mathbf{8 4 . 6 7}$ \\
Control & 2.18 & N.S & 1.49 & N.S & 1.00 & $\mathbf{4 . 1 6}$ \\
LSD 0.05 & & & & & &
\end{tabular}

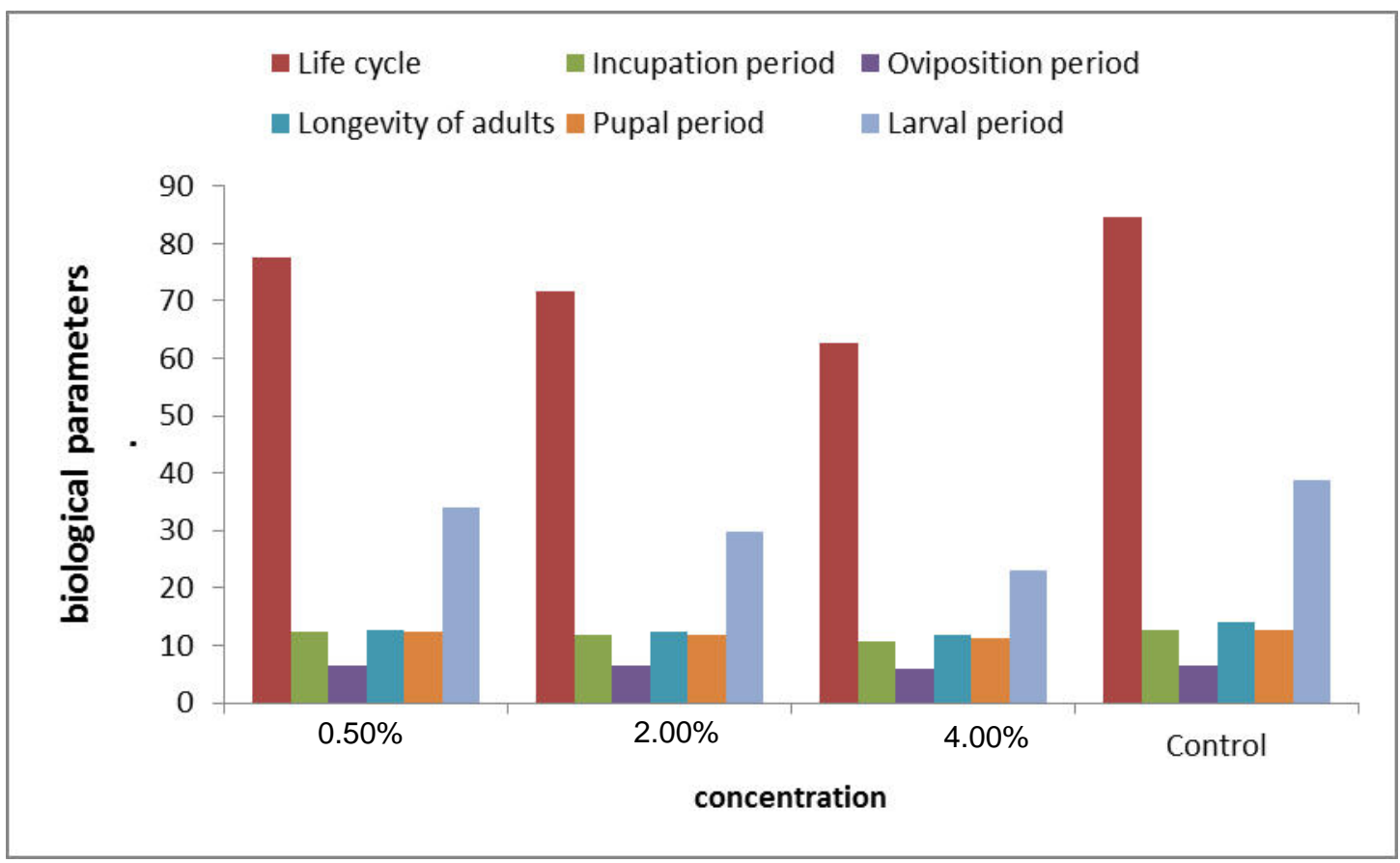

Figure 5. Effect of different concentrations of E. Camalulensis Dehn. extract on some biological aspects of $G$. mellonella under laboratory conditions 
The duration of larval and pupal stages, adult longevity, oviposition period and incubation period, decreased by increasing E. Camalulensis concentrations. There were significant differences for cases except for pupal and oviposition periods.

The obtained results are in agreement with those found by Patel et al., (1993). They found that $D$. stramonium $\mathrm{L}$. plant gave higher mortality within $24 \mathrm{hr}$. against logicorn.

Kumral et al., (2013) examined the ethanol extracts obtained from the leaf of the thorn apple (Datura stramonium L.) (Solanaceae) for lethal and repellent properties against adults of the European red mite Panonychus ulmi (Koch) (Acari: Tetranychidae) and its predator Stethorus gilvifrons (Muls.) (Col.: Coccinellidae) under laboratory conditions. The Petri leaf disc-spray tower method was used. The results showed that Datura stramonium leaf extracts were lethal to both the mite and its predator. Furthermore, an increase in the dose of leaf extract caused a significant increase in the death rates of both Panonychus ulmi and Stethorus gilvifrons adults.

Al-Ghannoum, and Karso, (2015) studied that Different concentrations $(25,30,35$ and $40 \%$ ) of Nerium oleander L. leaf extracts were tested against the red grain beetle adults Tribolium castaneum (Herbst). Results showed that the percentage mortality ranged from $16.7 \%$ in the powder treatment increased to $70 \%$ in the alcohol extract at $40 \%$ concentration. Highest mortality rate was $49.2 \%$ in the alcohol extract, followed by $43.4 \%$ in the aqueous extract, while the least $(30.9 \%)$ was recorded for the dry powder of $\mathrm{N}$. oleander leaves. The results also showed an attraction and repellent effects of the
Life cycle decreased by increasing $N$. oleander concentrations (62.67 days at 4 $\%$ concentration, 77.67 days at $0.5 \%$ in comparison with 84.67 day at control), with significant differences between concentrations and control.

extracts on the pest adults and there was a positive correlation between high mortality rate of the tested products and repellent effects on the adults, while a negative correlation was recorded between mortality rate and attractiveness.

\section{References}

Abbasipour,H., Rastegar, F., Mahmoud, V.M. and Hosseinpour, M. (2011) 'Insecticidal activity of extract from Datura stramonium (F.) (Solanaceae) against Callosobruchus maculatus'. IOBC/WPRS Bulletin; 2011. 69, pp.251-256.

Al-Ghannoum, M.I. and Karso, B.A. (2015) 'Biological potency of Nerium oleander L. leaf extracts on mortality of the red flour beetle Tribolium castaneum (Herbst) (Coleoptera: Tenebrionidae)'. Egyptian Journal of Biological Pest Control; 2015. 25(1), pp.135-138. 20 ref.

Ellis, A.M. and Hayes G.W. (2009) 'Assessing the efficacy of a product containing Bacillus thuringiensis applied to honey bee (Hymenoptera: Apidae) foundation as a control for Galleria mellonella (Lepidoptera: Pyralidae)', J. Entomol. Sci., 44(2), pp. 158-163.

Finney, D.J. (1971) 'Probit analysis', (Cambridge Univ. Press, London, 3rd ed., $318 \mathrm{pp}$ ). 
Gomez, K.A. and Gomez, A.A. (1984) 'Statistical procedures of agric', Res.John Wily and Sons, New York.

Hachiro A. and David A. (2000) 'Diagnosis of Honey Bee Diseases'. U. S. Department of Agriculture 'Agriculture handbook No. AH -690, $61 \mathrm{pp}$.

Kumral, N.A., Cobanoglu, S. and Yalcn, C. (2013) 'Sub-lethal and lethal effects of Datura stramonium L. leaf extracts on the European red mite Panonychus ulmi (Koch) (Acari: Tetranychidae) and its predator, Stethorus gilvifrons (Muls.) (Col.: Coccinellidae)', International Journal of Acarology, 39(6), pp.494-501.

Malika, B., Badiaa, O. and Farida, S. (2016) 'Study of the larvicidal activity of hydro-alcoholic extracts Nerium oleander L. and Ricinus communis L. on Tuta absoluta M'. VII International Scientific Agriculture Symposium, "Agrosym, 6-9 October 2016.

Pastagia, J.J. and Patel, M.B. (2007) 'Biology of Galleria mellonella L. on brood comb of Apis cerana F. I. Plant Protec'. Environ., 4 (2), pp. 85-88.

Roman, P.N.V. and Sera, B. (2009) 'Repellency and toxicity of three Impatlens species (Balsaminaceae) extracts on Myzus percicae'. J. Biopesticides, 2(1), pp. 48-51. 